\title{
Assessing the quality of the management skills required for lower respiratory tract infections in Kilimanjaro, Tanzania
}

\author{
Bernard Mbwele ${ }^{1,2}$ \\ ${ }^{1}$ Kilimanjaro Clinical Research Institute, Kilimanjaro Christian Medical Centre, Moshi, Tanzania; benmbwele@gmail.com \\ ${ }^{2}$ ART Project, Christian Social Service Commission, CSSC, Mwanza, Tanzania
}

Received 4 November 2013; revised 15 December 2013; accepted 26 December 2013

Copyright (C) 2014 Bernard Mbwele. This is an open access article distributed under the Creative Commons Attribution License, which permits unrestricted use, distribution, and reproduction in any medium, provided the original work is properly cited. In accordance of the Creative Commons Attribution License all Copyrights (c) 2014 are reserved for SCIRP and the owner of the intellectual property Bernard Mbwele. All Copyright (C 2014 are guarded by law and by SCIRP as a guardian.

\section{ABSTRACT}

Background: Lower respiratory tract infections (LRTI) are among the leading causes of morbidity and mortality. A severe form of atypical pneumonia, $Q$ fever, has been found in Northern Tanzania. Assessment of the quality of health care for lower respiratory tract infection from the clinicians' performance has rarely been performed. Methods: A cross sectional descriptive study using the qualitative and quantitative approaches for assessing clinicians and patient files from 11 health facilities of Kilimanjaro region. The facilities were of 4 different levels of public health care delivery and 1 private independent hospital. Results: Medications for LRTI were highly variable in $\mathbf{3 4 6}$ files and from attempts of treatment reported in 53 clinician's interviews. No file showed attempts for assessing the severity of Pneumonia. Only 6 (11.1\%) clinicians could mention causes of atypical pneumonia. Only 7 clinicians (13.0\%) were aware of Q-fever and could mention the cause. The quality of clinical records for monitoring the progress was not the same in all levels of care and the difference in availability was statistically significant as level of mental state $X^{2}(4)=139.4 ; P$ value $<0.001$, blood pressure $X^{2}(8)=75.2 ; P$ value $<0.001$, temperature $X^{2}(4)=78.7$; $P$ value $<0.001$, pulse rate $X^{2}(4)=139.1 ; P$ value $<0.001$, respiratory rate $X^{2}(4)=197.7 ; P$ value $<0.001$, auscultation $x^{2}(4)=92.2 ; \mathrm{P}$ value $<0.001$. Conclusion: National guidelines for LRTI in Tanzania shall include severity assessments and how to rule out atypical pneumonia using evidence base ap- proaches.

\section{KEYWORDS}

Quality; Health Care; Lower Respiratory Tract Infections; Tanzania; Sub-Saharan Africa

\section{BACKGROUND}

Since the beginning of WHO reports on Global Burdens of Diseases [1], lower respiratory tract infections (LRTI) have been reported to cause considerable morbidity and mortality worldwide [2-6]. They place a huge strain on the health budgets [7]. LRTI are responsible for an estimated $4 \%$ of all deaths in high income countries and for almost $7 \%$ of all cause mortality in low income countries $[8,9]$.

Microbial agents causing community acquired pneumonia (CAP) are the commonest causes of LRTI in sub Saharan Africa [4] in both HIV positive and HIV negative individuals [10]. The management of LRTI is complex due to the emerging drug resistant microorganisms [11]. It is now more evident in East Africa [12] that resistance jeopardises outcome of care. Following diversity in causality, severity and resistance patterns guiding management of LRTI is of paramount importance [13]. This has resulted in various national and international guidelines for the management of CAP in the developed world $[14,15]$.

The most important guide is the assessment for the severity of the LRTI to guide management options by scores. One of clinical scores is CURB-65 (or in its simplified form CRB-65) by British Thoracic Society rules [14] and the other one pneumonia severity index (PSI) by American thoracic society (ATS)/Infectious diseases society of America (IDSA) [16-18]. 
Atypical pneumonia caused by Chlamydia pneumoniae, Mycoplasma pneumoniae, Legionella pneumophila, Chlamydia psittaci (psittacosis), Francisella tularensis (tularemia), and Coxiella burnetii (Q fever) $[19,20]$ tends to present as a severe form of LRTI. Studying the epidemiology of atypical pneumonia is emerging to be of vital importance in East Africa (tropic countries) as in the temperate areas [21]. Currently, the incidence of infections with atypical micro-organisms such as Q-fever [22] or Legionella [23] is unknown, while those with known trends HIV and TB are further studied [24-26]. However, there is an advance in the management of atypical pathogens causing LRTI in developed temperate countries [2729] than in the tropics. This scenario might be explained by the difficulty in culturing and the expense of serology. The guidelines for management of LRTI and atypical pneumonia will be more useful in the tropics diagnostic facilities and treatment options are often suboptimal.

While almost all high-income countries have national guidelines on LRTI's, there are only few countries in sub-Saharan Africa using LRTI guidelines [17]. Countries with a particular guideline in LRTI often do not actively monitor the adherence of such guidelines [30]. Evidence exists in that guidelines for LRTI in sub-Saharan Africa are often not followed, leading to longer hospital stay and increased mortality [30-32].

In Tanzania, patients with LRTI are managed by the standard treatment guideline [33]. Little is known about health care workers' (HCW) theoretical knowledge of LRTI and their daily practice for LRTI. Moreover, there is little insight in barriers they may experience while trying to provide optimal care, such as limited diagnostic facilities or lack of antibiotics. The aim of this project was to assess the current diagnostic and treatment practices in patients with LRTI in different health care settings in Tanzania.

\section{METHODS}

\subsection{Study Design}

The cross sectional study using both qualitative and quantitative methods. The study was conducted in the 11 hospitals of different levels of care in Tanzania.

The study population included health care providers (clinicians) from 11 facilities of Kilimanjaro region in northern in Tanzania. The 10 facilities were public with 4 different levels of health care i.e. 1 zonal referral, 1 regional hospital, 4 district hospital and 4 health centers and the 11th was the independent private church based hospital. Data was collected by a semi-structured interview with HCW on their management of LRTI and 2 assessments of case record files of admitted patients with a LRTI.

By purposive sampling technique only clinicians who have been working in internal medicine and or outpatient and causality, where patients with lower respiratory tract infections have been attended. From the list of clinicians available in the facility, a sample that covers a half or more of the clinicians was framed.

\subsection{Sampling}

Clinicians who have been working in internal medicine or outpatient clinic for the past 12 months with the possibility of seeing patients with LRTI were selected. Within the sample all levels clinicians at a proportion of $50 \%$ or more was used (a minimum of 10 clinicians).

For medical records, files of the patients who have been admitted in the hospital primary due to lower respiratory tract infection selected. By purposive sampling technique, hospital files were recruited from the list admitted patients with LRTI. Hospital files that show admission history in the past 6 months to 1 year was collected. Files of the patients admitted with many different diseases and files of the patients who have never been admitted were excluded.

\subsection{Data Collection}

Semi-structured interviews on dummy patients were conducted to study the current practice by clinicians. Two dummy cases of different presentation were described and then clinicians were asked to give responses on what they think might be appropriate in managing the patient with lower respiratory tract infection. Two dummy cases were used in the interview reflecting severity of illnesses. A first case was for a 55 year old male who presented with cough for 10 days, fever and shortness of breath. A second one was for 68 year old woman who presents at the OPD (Out-Patient Department) with a history of productive cough for one week, a breathing rate of 32 breaths/min and a blood pressure of $85 / 55 \mathrm{mmHg}$. Where the information was further needed probing for inner insight was done. Guided interviews were used to collect information from clinicians regarding what is used in reaching the diagnosis, assessing the severity of disease and treating the patients.

A guided data extraction was executed so as to compare current healthcare as provided with care as recommended. A review of patient files for the diagnoses and prescriptions was conducted. Then all files that were indicated by the admission book to contain any of the diagnosis of lower respiratory tract infection were recorded by registration numbers and then traced in the medical record unit. Matched names and hospital registration number was used to recruit files into the study.

\subsection{Data Analysis}

Data from the questionnaires and case report forms were entered in Microsoft Access 2007 database. Data cleaning was done by the principle investigator and 
the IT data manager. Data were stored in a database with two data sets made by Microsoft Access 2007. Data on records and those from the interviews were analyzed by STATA v10 StataCorp, TX, USA).

Narratives were manually analyzed by Excel 2007, transcription into themes which were coded by footnotes and sub-coded into various categories which were then manually counted so as to gather summary information. For each striking finding in the qualitative narrative that provides evidence, was explored and described into meaningful results from which we could draw conclusion of the study we have conducted.

\subsection{Ethics}

Ethical approval was obtained from Local Ethical committee of Kilimanjaro Christian Medical College bearing number 477. Then a letter of approval was submitted to the regional medical officers and districts medical officers, then to Medical officer in-charges of the hospital facilities. Before the interviews the medical officer in charges and hospital administrators were given a leaflet of study information. Then a written signed consent was obtained for accessing hospital files. In parallel to this, hospital administration teams will be asked for arranging appointments the interviews, and then the consent was obtained from health workers. Information from the patient's files was entered using new codes that have been defined by the study designed.

\section{RESULTS}

\subsection{From the Interviews}

We were able to study a total of 53 narratives from the clinicians' interviews and 346 case report forms from 365 patient files were collected from 11 health facilities (19 files were excluded by age and diagnosis) (see Table 1 ). From the interviews, one had to be excluded because it was incomplete. Table 2 shows an overview of the number of interviews and CRF per facility. A total of 54 interviews with an asymmetrical distribution of qualifications and an average experience of 7.7 years \pm 8.3 years, minimum of 0.17 years and a maximum of 38 years.

Fourteen (25.9\%) reported having had training for diagnosis and management of TB, LRTI and/or TB in HIVinfected patients or training in LRTI in children.

Regarding the causes of atypical pneumonia only 6 (11.1\%) clinicians could mention microorganisms causing atypical pneumonia. Chlamydia spp was mentioned five times, Legionella spp three times, Mycoplasma spp three times and Coxiella burnetii once. From these clinicians three were medical officer registrars; one was a resident, one a junior specialist and one a senior specialist. Only 7 clinicians (13.0\%) Clinicians-mentioned to be aware of Q-fever and could mention the cause of Q-fever. Three of these clinicians were medical officer registrars from the designated district hospitals (Church supported), three were residents from the referral hospital and one was a junior specialist from the referral hospital.

None of the clinicians interviewed mentioned a scor-

Table 1. Summary of the hospital facilities, clinicians and patients studied.

\begin{tabular}{|c|c|c|c|c|c|}
\hline Facility CODE & Level of facility & Support & District location & No. of interviews & No. of case report files \\
\hline $\mathrm{F} 01$ & District hospital & Government based & Hai District & 8 & 41 \\
\hline F02 & Health center & Government based & Hai District & 4 & 21 \\
\hline F03 & Regional hospital & Government based & Moshi District & 6 & 31 \\
\hline F04 & District hospital & Government based & Siha District & 5 & 14 \\
\hline F05 & Health center & RK church based & Siha District & 2 & 18 \\
\hline F06 & District hospital & Government and church based & Moshi Rural District & 8 & 41 \\
\hline F08 & Health center & Government based & Moshi District & 5 & 25 \\
\hline F09 & District hospital & Church based & Moshi District & 4 & 30 \\
\hline F10 & Health center & Government based & Moshi Rural District & 2 & 21 \\
\hline F11 & Referral hospital & Government and church based & Moshi District & 6 & 93 \\
\hline
\end{tabular}

Table 2. Clinicians' experience of working for the respiratory diseases by the level of qualification.

\begin{tabular}{|c|c|c|c|c|c|c|c|}
\hline \multirow{2}{*}{ Duration of experience in years } & \multicolumn{6}{|c|}{ Qualification of the HCW } & \multirow{2}{*}{ Total } \\
\hline & $\mathrm{CO}$ & AMO & MO registrar & Resident & Jr Spec & Sr Spec & \\
\hline$<1.00$ & 5 & 1 & 1 & 0 & 0 & 0 & 7 \\
\hline $1.00-4.99$ & 8 & 5 & 2 & 4 & 1 & 0 & 20 \\
\hline $5.00-9.99$ & 4 & 6 & 1 & 0 & 0 & 1 & 12 \\
\hline $10.00-24.99$ & 5 & 6 & 0 & 0 & 0 & 1 & 12 \\
\hline $25.00+$ & 0 & 1 & 1 & 0 & 0 & 0 & 2 \\
\hline Total & 22 & 19 & 5 & 4 & 1 & 2 & 53 \\
\hline
\end{tabular}

HCW = health care worker, CO = clinical officer, AMO = assistent medical officer, $\mathrm{MO}$ reg = medical officer registrar, Res = resident, Jr Spec = junior specialist, $\mathrm{Sr}$ Spec = senior specialist. 
ing system like PSI or CRB-65. Some clinicians mentioned the use of some parameters of the CRB-65 in their assessment of severity; however they did not refer to the specific scoring system. The level of consciousness was mentioned by 5 (9.3\%) clinicians and the respiratory rate by $14(25.9 \%)$. Age was only mentioned once and the level of blood pressure was not mentioned at all. Assessment of severity was mostly mentioned to be done on clinical findings related to the respiratory system and other results of the laboratory investigations. Decision to admit or to treat the patient at OPD is shown in Table 3.

There was no clear evidence on what guides clinicians to decide when, where and how to treat the patient with LRTI. A total of 50 (92.6\%) clinicians would start treatment immediately after examination and/or reaching the provisional diagnosis. Three clinicians would say the patient should start with their treatment at home. One clinician will only start treatment immediately if the temperature was above the $38^{\circ} \mathrm{C}$.

For inpatient the clinicians mainly monitor the patient clinically through the vital signs measured by nurses, clinical improvement of the patient and findings on physical examination. Most clinicians visit their patients daily during ward rounds. For outpatients monitoring is more difficult. Most clinicians ask the patient to come back to the hospital if the medication does not work. Some ask the patient to come back after a certain amount of days varying from 2 to 7 days.

Majority of the clinicians would treat the Lower respiratory tract infection patients empirically in the first attempts (see Tables 4, 5 and Tables A1-A3 where the later shows differences in prescriptions by the level of health care delivery from a referral hospital, regional hospital, district hospital, health centers and one independent church based hospital). These medications were mentioned to be monotherapy of benzylpenicillin, amoxycillin, cloxacillin or Ampicillin. Alternatively benzylpenicillin for 72 hrs followed by ampicillin first choice. The double combined therapy of ampicillin/benzylpenicillin with aminoglycosides was spared mostly for severe forms. Two clinicians mentioned combination therapy directed at both typical and atypical pathogens. One clinician wanted to give erythromycin, which covers both types of pathogens. Erythromycin was also included as alternative for preferred initial treatment by three clinicians.

Third generation cephalosporin were commonly used in the second attempts for LRTI treatment. For example in the first attempt by amoxicillin orally, cephalosporin were 13 out of 22 for the none sever form and 7 out of 24 for the sever one. For the IV benzylpenicillin, cephalosporin were 7 out of 15 from the non severe form of LRTI and 6 out of 8 among the sever one. For IV benzylpenicillin and followed by oral amoxicillin, 2 out of 4 second attempts were cephalosporin. However for amoxicillin/ampicillin and gentamycin, 1 or none of the second attempts were cephalosporin as there was a higher attempts to refer patients in this scenario.

\subsection{From the Files}

A total of 346 case files were studied where the average age of patients was $48.19 \pm 22.02$ years with a range of 18 to 107 years. The description of history of illness by the chief complaints and duration illnesses before presenting to the Hospital facility is described in Table 6. The attempts of clinician to do physical examination for the patients are shown in Figure 1.

Table 3. Clinicians' management fornon severe LRTI and severe LRTI.

\begin{tabular}{|c|c|c|}
\hline $\begin{array}{l}\text { Criteria of the } \\
\text { management }\end{array}$ & Case 1 (mild LRTI) & Case 2 (severe LRTI) \\
\hline $\begin{array}{l}\text { Most probable } \\
\text { Micro-organisms } \\
\text { causing LRTI }\end{array}$ & $\begin{array}{l}161 \text { agents mentioned from } 52 \text { Clinicians. Streptococcus } \\
\text { pneumoniae } 47 \text { times ( } 87.0 \%) \text {, Haemophilus influenza } 20 \\
\text { (37.0\%), Staphylococcus spp } 16 \text { times ( } 29.63 \%) \text {, Mycobacte- } \\
\text { rium tuberculosis } 14 \text { ( } 25.9 \%) \text {. Mycoplasma } 2 \text { times ( } 3.7 \%) \text {, } \\
\text { Legionella pneumophila } 2 \text { times (3.7\%) and Chlamydia spp } 1 \\
\text { (1.8\%). None of the interviewed named Coxiellaburnettii. Oth- } \\
\text { ers Para-influenza virus, RSV, Pneumocystis jiroveci, } \\
\text { Campylobacter spp, unspecified nosocomial infections. }\end{array}$ & $\begin{array}{l}149 \text { agents from } 52 \text { Clinicians, Streptococcus pneumoniae } 44 \\
\text { times (84.6\%), Staphylococcus aureus } 30 \text { times (57.7\%), M. } \\
\text { tuberculosis } 16 \text { times ( } 30.8 \%) \text { and Haemophilus influenza } 10 \\
\text { times (19.2\%). Legionella } 8 \text { times (5.4\%), Chlamydia } 6 \text { times } \\
\text { (4.0\%) and Mycoplasma } 6 \text { (4.0\%). Coxiellaburnetii was again } \\
\text { not mentioned. Other micro-organisms mentioned included: } \\
\text { PCP, Ricketsia spp, HIV, Ducli-Haemophilus, Para-influenza, } \\
\text { unspecified anaerobic bacteria and fungal infections. }\end{array}$ \\
\hline $\begin{array}{l}\text { Diagnostic } \\
\text { tests preferred }\end{array}$ & $\begin{array}{l}\text { Chest X ray } 90.6 \% \text {, Full Blood Picture } 58.5 \% \text {, AFB test } 49.1 \% \text {, } \\
\text { ESR } 43.4 \% \text {, Sputum Culture } 20.8 \% \text {, Blood culture } 5.6 \% \text {, Lung } \\
\text { function test 5.6\%, Bronchosopy } 0.0 \% \text {, BAL } 0.0 \% \text {. }\end{array}$ & $\begin{array}{l}\text { Chest X ray } 78.4 \% \text {, Full Blood Picture } 60.8 \% \text {, AFB test } 58.8 \% \text {, } \\
\text { ESR } 41.1 \% \text {, Sputum Culture } 25.5 \% \text {, Blood culture } 17.7 \% \text {, Lung } \\
\text { function test } 5.8 \% \text {, Bronchosopy } 5.8 \% \text {, BAL } 0.0 \% \text {. }\end{array}$ \\
\hline $\begin{array}{l}\text { Place of } \\
\text { treatment }\end{array}$ & $\begin{array}{l}\text { OPD medication at home } 14.8 \% \text {, Start medication at OPD then } \\
\text { home } 13.0 \% \text {, Admit and treat in the ward } 68.5 \% \text {, ICU } 0.0 \% \text {, } \\
\text { Refer immediately } 1.9 \% \text {, Missing } 1.9 \% \text {. }\end{array}$ & $\begin{array}{l}\text { OPD medication at home } 13.0 \% \text {, Start medication at OPD then } \\
\text { home } 11.1 \% \text {, Admit and treat in the ward } 64.8 \% \text {, ICU } 5.6 \% \text {, } \\
\text { Refer immediately } 3.7 \% \text {, Missing } 1.9 \% \text {. }\end{array}$ \\
\hline $\begin{array}{l}\text { First choice } \\
\text { treatment }\end{array}$ & $\begin{array}{l}\text { Benzylpenicillin iv or im16 (29.6\%), Ampicillin and } \\
\text { gentamycin } 11 \text { (20.4\%), Amoxicilline oral 10(18.5\%), } \\
\text { Ampicillin iv } 3 \text { (5.6\%), Benzylpenicilline and chloramphenicol } \\
2 \text { (3.7\%). Benzylpenicilln and gentamycin2 (3.7\%), Ampiclox } \\
\text { (cloxacillin and ampicillin) } 2 \text { (3.7\%), Chloramphenicol single } \\
\text { therapy2 (3.7\%), Amoxicillin-clavulanic acid and azithromycin } \\
1(1.9 \%) .\end{array}$ & $\begin{array}{l}\text { Amoxicillin } 24 \text { (44.4\%), Benzylpenicillin 814.81\%), } \\
\text { Benzylpenicillin and then amoxicillin } 4 \text { (7.4\%), Cloxacillin } 3 \\
\text { (5.6\%), Anti-TB treatment } 2 \text { (3.7\%), Ceftriaxone } 2 \text { (3.7\%), } \\
\text { Cotrimoxazole2 (3.7\%), Gentamycin } 2 \text { (3.7\%). }\end{array}$ \\
\hline
\end{tabular}


Table 4. The second and third attempt of treatment given after treatment failure in Case 1.

\begin{tabular}{|c|c|c|c|c|c|}
\hline First mentioned treatment & & Second attempt & \multicolumn{3}{|c|}{ Third attempt } \\
\hline \multirow{13}{*}{ Amoxicilline } & \multirow{13}{*}{22} & \multirow{5}{*}{ Cephalosporin, ceftriaxone } & \multirow{4}{*}{13} & Refer & 5 \\
\hline & & & & Further investigations & 3 \\
\hline & & & & Discuss with coworkers & 2 \\
\hline & & & & Consider TB & 2 \\
\hline & & & & Cocktail of antibiotics ${ }^{*}$ & 1 \\
\hline & & Continue amoxicillin treatment & 2 & Further investigations & 2 \\
\hline & & & & Refer & 1 \\
\hline & & Benzylpenicillin chloramphenicol & 2 & Further investigations & 1 \\
\hline & & & & Benzylpenicillin & 1 \\
\hline & & Erythromycin & 2 & Further investigations & 1 \\
\hline & & Cloxacillin & 1 & Benzylpenicillin & 1 \\
\hline & & Benzylpenicillin and gentamycin & 1 & Discuss with coworkers & 1 \\
\hline & & Broader spectrum antibiotics & 1 & Further investigations & 1 \\
\hline & & & & Refer & 4 \\
\hline & & Ceftriaxone & 7 & Further investigations & 2 \\
\hline & & & & Consider TB & 1 \\
\hline & & Add erythromycin & 1 & Further investigations & 1 \\
\hline Renzylnenicilline & 15 & Add gentamycin & 1 & Further investigations & 1 \\
\hline Benzylpenıcillıne & 15 & Chloramphenicol & 1 & Further investigations & 1 \\
\hline & & Amoxicillin & 1 & Ceftriaxone & 1 \\
\hline & & Cloxacillin & 1 & Discuss with coworkers & 1 \\
\hline & & Refer & 1 & & \\
\hline & & Further investigations & 2 & & \\
\hline & & Gentamycin & 1 & & \\
\hline Benzylpenicilline and amoxicilline & 3 & Chloramphenicol & 1 & Refer & 2 \\
\hline & & Further investigations & 1 & Ceftriaxone & 1 \\
\hline Amniclox & 2 & Gentamycin and chloramphenicol & 1 & Refer & 1 \\
\hline & 2 & Ceftriaxone & 1 & Futher investigations & 1 \\
\hline Chloramphenicol & 2 & Benzylpenicillin & 1 & Ceftriaxone & \\
\hline Chloramphenicol & 2 & Amoxicillin and gentamycin & 1 & Ceftriaxone & 2 \\
\hline Gentamycin & 2 & Cotrimoxazole & 1 & Further inyestioations & 2 \\
\hline Gentamycin & 2 & Ceftriaxone & 1 & Further investigations & 2 \\
\hline Amoxicillin-clav & 1 & Cephalosporins & 1 & Consider TB & 1 \\
\hline Amoxicilline and gentamycin & 1 & Broader spectrum antibiotics & 1 & Further investigations & 1 \\
\hline Benzylpenicilline and chloramphenicol & 1 & Ceftriaxone & 1 & Refer & 1 \\
\hline Ceftriaxone & 1 & Anti-TB treatment & 1 & Fungal & 1 \\
\hline Cotrimoxazole & 1 & Ciprofloxacin & 1 & Ceftriaxone & 1 \\
\hline Erythromycin & 1 & Amoxicillin & 1 & Further investigations & 1 \\
\hline Flucamox & 1 & Cephalaxin & 1 & Discuss with coworkers & 1 \\
\hline Paracetamol and await results & 1 & & & & \\
\hline
\end{tabular}

${ }^{*}$ Cocktail of antibiotics: cephalosporins, knamycin, amikcin and gentamycin.

The trends of performing investigations and prescription found from the files are shown in the Figures 2 and 3. Most of the tests like were not performed in the health centers due to unavailability of the radiography at the level of the health centers. HIV and AFB tests were performed at a frequency of 64 and 69 times respectively. The frequency was determined by the strength of internal audits and hospital based staff motivation. HIV test results were positive at a frequency of 33 (51.6\%) and AFB were positive at a frequency of 22 files (31.9\%).

\subsection{CURB 65 Matrix}

It was possible to ascertain the use of CURB 65 parameters in a quarter of the files we assessed. This is because there were 89 files (25.72\%) with records of the level of mental state. The possibilities for performing CRB 65 from the data we captured are shown in Table 7. The antibiotics that were prescribed are shown in Figure 3. Anti-TB treatment was prescribed in 27 (7.8\%) of the cases. 
Table 5. Second and third attempt after treatment failure in Case 2.

\begin{tabular}{|c|c|c|c|c|c|}
\hline First mentioned treatment & & Second attempt & & Third attempt & \\
\hline \multirow{17}{*}{ Amoxicillin } & \multirow{17}{*}{24} & \multirow{3}{*}{ Cephalosporin, ceftriaxone } & \multirow{3}{*}{7} & Refer & 3 \\
\hline & & & & Further investigations & 3 \\
\hline & & & & Discuss with coworkers & 1 \\
\hline & & \multirow{3}{*}{ Add gentamycin } & \multirow{3}{*}{3} & Refer & 1 \\
\hline & & & & Further investigations & 1 \\
\hline & & & & Discuss with coworkers & 1 \\
\hline & & Erythromycin & 2 & Further investigations & 2 \\
\hline & & \multirow{2}{*}{ Cotrimoxazole } & \multirow{2}{*}{2} & Benzylpenicillin & 1 \\
\hline & & & & Further investigations & 1 \\
\hline & & \multirow{2}{*}{ Chloramphenicol } & \multirow{2}{*}{2} & Cephalosporins & 1 \\
\hline & & & & Further investigations & 1 \\
\hline & & Benzylpenicillin and amoxicillin & 1 & Refer & 1 \\
\hline & & More broad spectrum antibiotics & 1 & Consider atypical pneumonia & 1 \\
\hline & & Continue treatment with amoxicillin & 1 & Cotrimoxazole & 1 \\
\hline & & Anti-histamine & 1 & Further investigations & 1 \\
\hline & & Further investigations & 2 & & \\
\hline & & Refer & 2 & & \\
\hline \multirow{7}{*}{ Benzylpenicillin } & \multirow{7}{*}{8} & \multirow{4}{*}{ Cephalosporin, ceftriaxone } & \multirow{4}{*}{6} & Refer & 2 \\
\hline & & & & Further investigations & 2 \\
\hline & & & & Cloxacillin & 1 \\
\hline & & & & Anti-TB treatment & 1 \\
\hline & & Erythromycin & 1 & Further investigations & 2 \\
\hline & & Amoxicillin & 1 & Further investigations & 2 \\
\hline & & Ceftriaxone & 2 & & \\
\hline \multirow[t]{2}{*}{ Benzylpenicillin and amoxicillin } & \multirow[t]{2}{*}{4} & Chloramphenicol & 1 & Refer & 4 \\
\hline & & Erythromycin & 1 & & \\
\hline \multirow{3}{*}{ Cloxacillin } & \multirow{3}{*}{3} & \multirow{2}{*}{ Ceftriaxone } & \multirow{2}{*}{2} & Refer & 1 \\
\hline & & & & Anti-TB treatment & 1 \\
\hline & & Available alternative treatment & 1 & Further investigations & 1 \\
\hline \multirow{2}{*}{ Anti-TB treatment } & \multirow{2}{*}{2} & Another anti-TB treatment & 1 & Further investigations & 1 \\
\hline & & Missing & 1 & & \\
\hline \multirow{2}{*}{ Ceftriaxone } & \multirow{2}{*}{2} & Carbendazim & 1 & Further investigations & 1 \\
\hline & & Add cloxacillin and erythromycin & 1 & If HIV positive: add cotrimoxazole & 1 \\
\hline \multirow{2}{*}{ Cotrimoxazole } & ? & Amoxicillin & 1 & Further investigations & 1 \\
\hline & 2 & Further investigations & 1 & & \\
\hline Gentamycin & 2 & Ceftriaxon & 2 & Further investigations & 2 \\
\hline Digoxin & 1 & Losartan & 1 & Discuss with coworkers & 1 \\
\hline Furosemide & 1 & Refer the patient & 1 & & 1 \\
\hline Hydrocortisone & 1 & Amoxicillin and gentamycin & 1 & Cephalosporin & 1 \\
\hline IV fluids & 1 & Ringer lactate & 1 & Discuss with senior & 1 \\
\hline Erythromycin & 1 & Refer the patient & 1 & & \\
\hline Missing & 2 & & & & \\
\hline
\end{tabular}

Table 6. Chief complaints as found from the files of admitted patients.

\begin{tabular}{ccccc}
\hline Chief complaints & Frequency & Proportion & No. of files with durations known & Median days (range) \\
\hline Dry cough & 168 & $50.9 \%$ & $116(69.1 \%)$ & $3.50(\min 1, \max 730)$ \\
Productive cough & 92 & $27.8 \%$ & $63(68.5 \%)$ & $7.00(\min 1, \max 365)$ \\
Difficult breathing & 93 & $28.2 \%$ & $64(68.8 \%)$ & $5.00(\min 1, \max 180)$ \\
Fever & 119 & $36.1 \%$ & $80(67.2 \%)$ & $3.00(\min 1, \max 365)$ \\
Chest pain & 135 & $40.9 \%$ & $86(63.7 \%)$ & $4.00(\min 1, \max 1825)$ \\
Chest tightness & 79 & $23.9 \%$ & $48(60.8 \%)$ & $3.00(\min 1, \max 730)$ \\
\hline
\end{tabular}

The reason for admission has not been included in the analysis, because it was often not described why a patient had been admitted. 


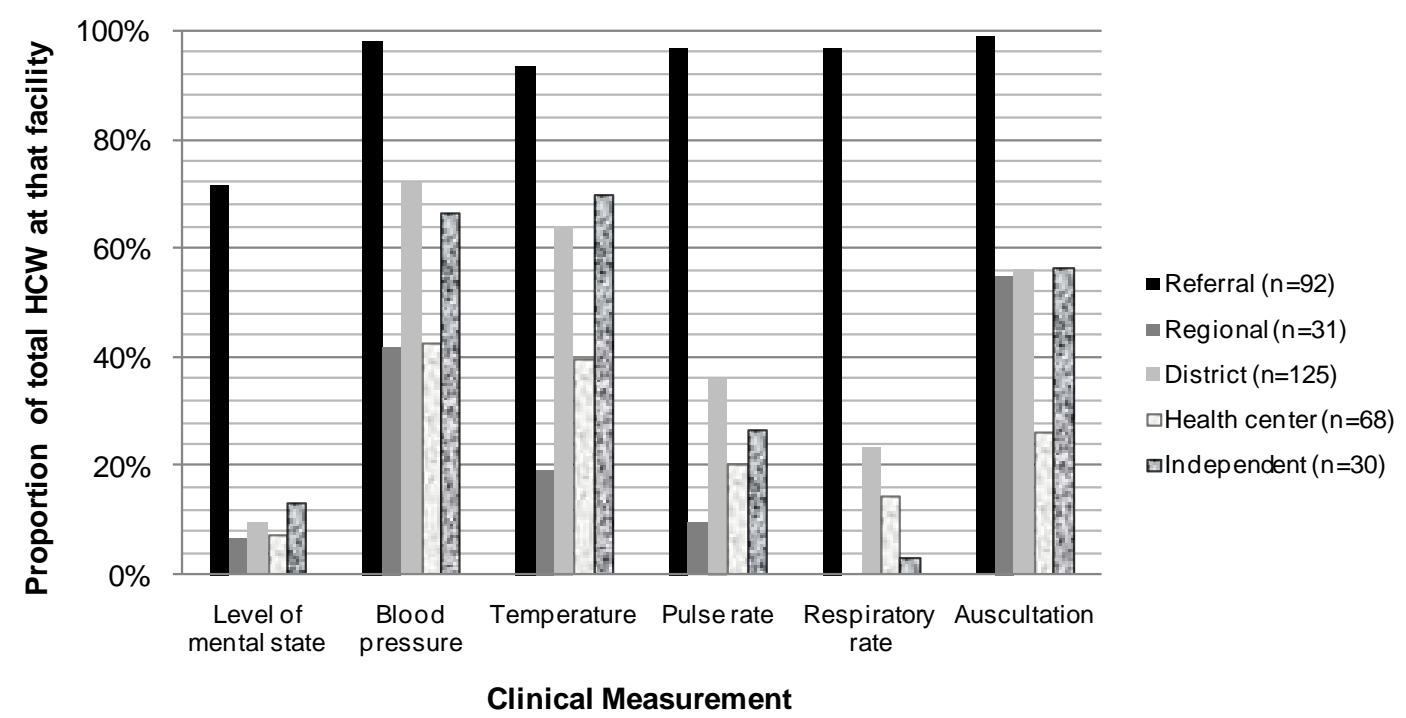

Level of mental state $\chi^{2}(4)=139.4154$, P value $<0.001$, Blood pressure $\chi^{2}(8)=75.2312$, P value $<0.001$, Temperature $\chi^{2}(4)=$ 78.7069, P value $<0.001$, Pulse rate $\chi^{2}(4)=139.0601$, P value $<0.001$, Respiratory rate $\chi^{2}(4)=197.7278$, P value $<0.001$, Auscultation $\chi^{2}(4)=92.1555$, P value $<0.001$.

Figure 1. Clinical measurements that were recorded per level of facility.

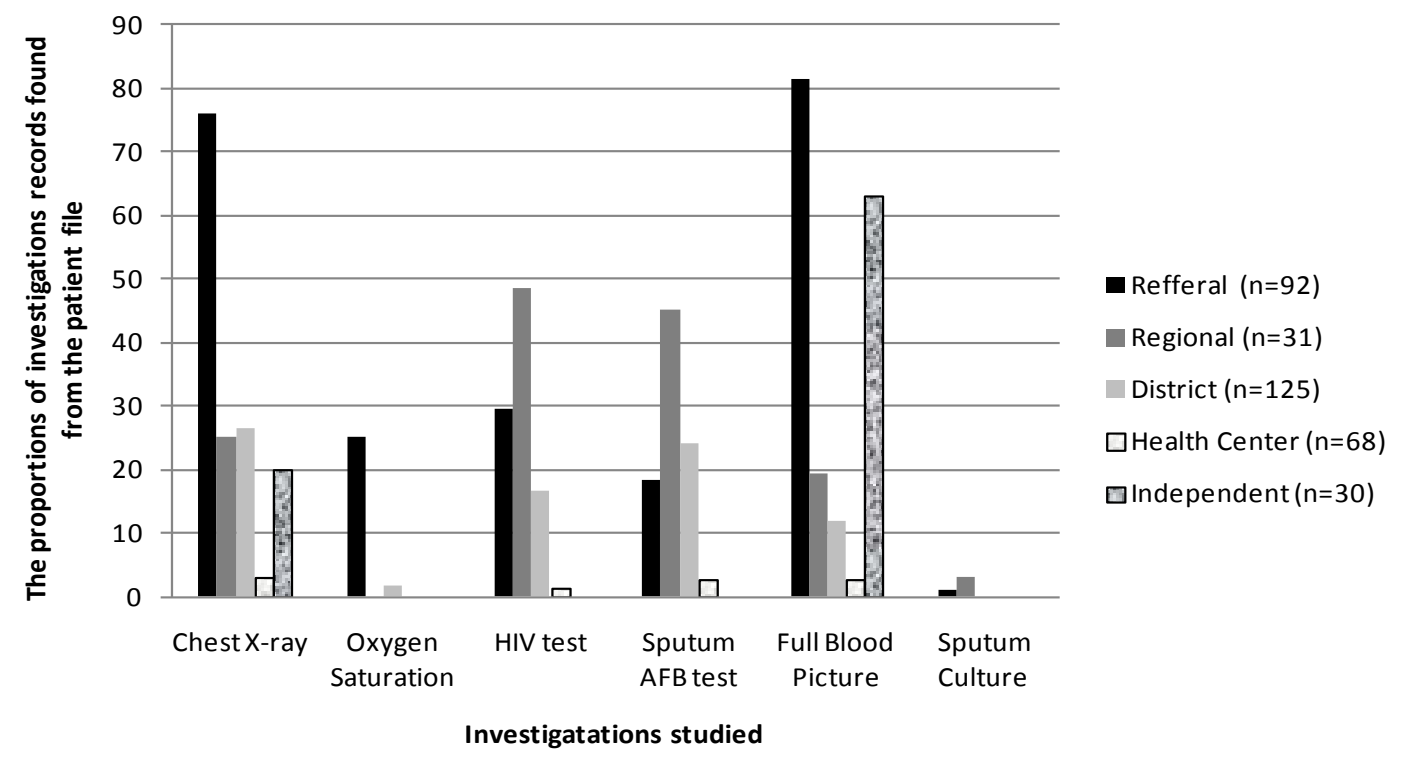

Chest $\mathrm{x}$ ray $\chi^{2}(8)=130.4546$, P value $<0.001$, Oxygen saturation $\chi^{2}(4)=59.3082$, P value $<0.001$, HIV test $\chi^{2}(4)=41.6205$, P value $<0.001$, Sputum for AFB $\chi^{2}(4)=29.7077$, P value $<0.001$, Full blood picture $\chi^{2}(4)=163.6747$, P value $<0.001$, Sputum Culture $\chi^{2}(4)=5.4928$, P value $=0.240$.

Figure 2. Laboratory investigation as shown in the files.

Table 7. The CRB-65 score of the case files in which the CRB65 could be measured.

\begin{tabular}{cccc}
\hline Severity & CRB-65 score & frequency & $\begin{array}{c}\text { Proportions of } \\
\text { measurable CRB-65 }\end{array}$ \\
\hline \multirow{2}{*}{ Non-severe } & 0 & 18 & $26.9 \%$ \\
\multirow{2}{*}{ Mild } & 1 & 26 & $38.8 \%$ \\
& 2 & 13 & $19.4 \%$ \\
\multirow{2}{*}{ Severe } & 3 & 10 & $14.9 \%$ \\
& 4 & 0 & $0 \%$ \\
& 5 & 0 & $0 \%$ \\
\hline
\end{tabular}

\subsection{Outcome of Care of the Patient Files}

The patients files showed that the majority of patients admitted with LRTI in the region were discharged with further treatments. The outcome of death was ranking the second of all possible outcome of care studied as shown in Figure 4.

\section{DISCUSSIONS}

Clinicians in Kilimanjaro region are not well informed 


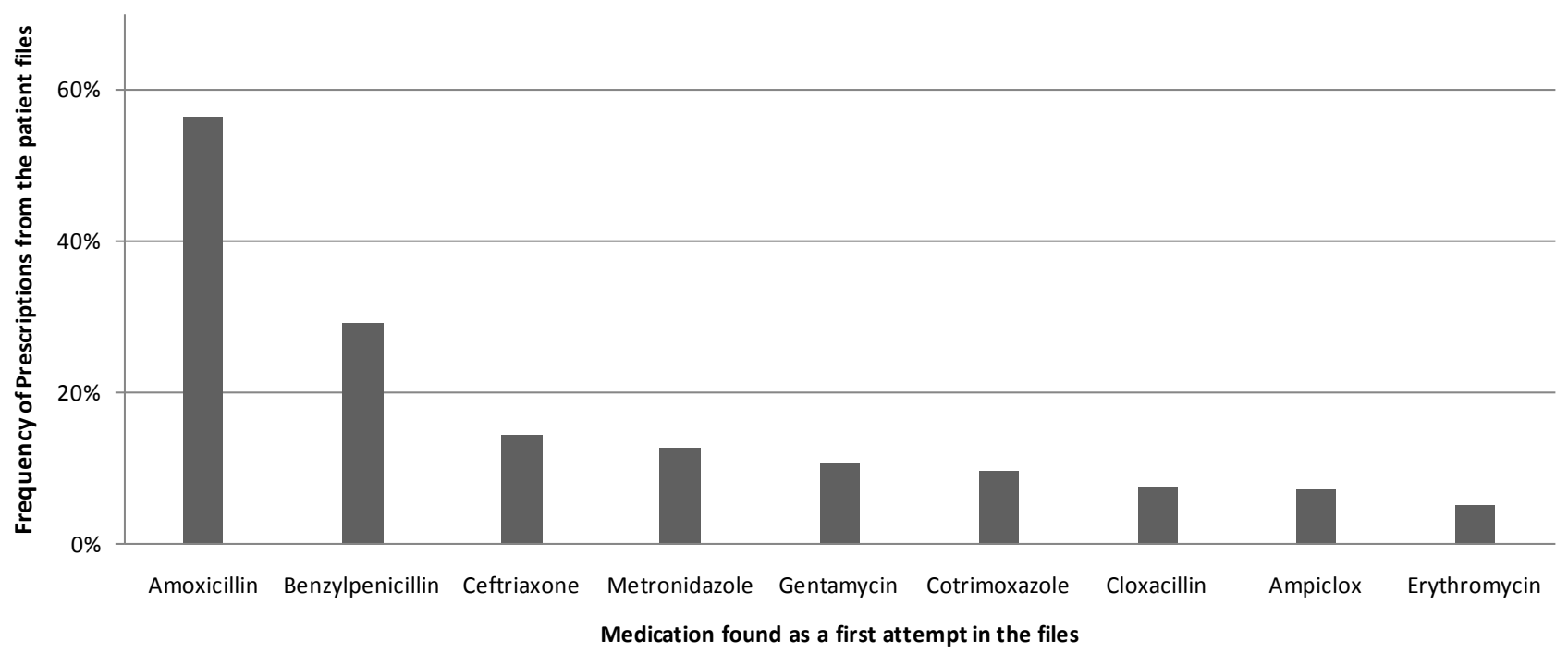

Figure 3. Antibiotics as prescribed in the patient files.

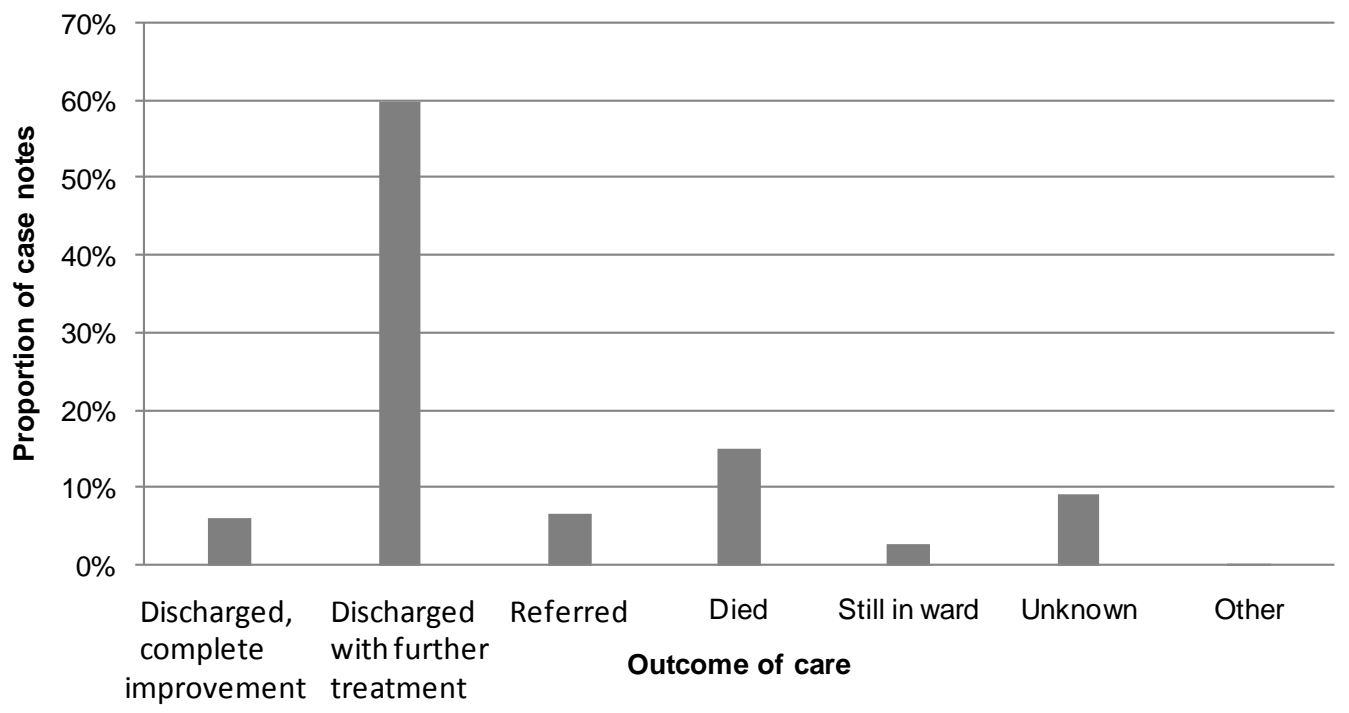

Figure 4. Outcome of care from patients with LRTI.

on the principles of management of LRTI. While Clinicians are guided by the Standard Treatment Guideline [33] and the TB/HIV manual for Clinicians in Tanzania [34], hardly clinicians could mention these guidelines to be in use. Despite massive efforts to diagnose [24] and treat Tuberculosis [25] a thin line of lung infection is forgotten and leave clinicians into dilemma.

Our findings from patient files assessment was similar to local audits that can be routinely performed in the health facilities of Kilimanjaro region, then Tanzania and sub Saharan Africa in general.

Most patient files in the hospitals of Kilimanjaro region presented with dry cough and chest pain as chief complaints. However, there was a strong tendency of clinicians not to write the duration of symptoms presented. physical examination was often not performed and there was a high tendency of missing out of the records of care.

In addition from invariable explanations from Clinicians, patients' files have reveals no clear tool or score chart to be followed for the assessment of severity and choice of treatment regimen for LRTI. This means most of decisions to admit or to release the patient for home care were not well guided. Evidence from the files studied showed that CRB-65 [18] score could be calculated from only $20 \%$ of patient files.

The diagnostic tests such a chest X-ray is variably unavailable at district hospitals and not available at all in health centres where most of patient with LRTI are seen for primary care. Our study from the files reveals chest $\mathrm{X}$-ray to be requested in only 33\% of patients, compared to the $90 \%$ of clinicians who stated to wish to perform a 
chest X-ray in the interviews. Sputum gram stain test was found to be not in practice for most of cases with sign and symptoms of LRTI despite attempt of requesting Sputum for AFB at 25\%. While there is an emphasis on PITC in Tanzania [35], rarely HIV test was performed [36] despite higher proportions of seropositive results among admitted patients tested.

Clinicians often present with experience of irrational antibiotic prescriptions for LRTI. For example, antibiotics covering gram negative pathogens aminoglycosides were prescribed at a proportion higher than expected. While unguided third generation cephalosporin were prescribed after each finding of a clinical failure. This is not in line with the recommendations from Tanzania standard treatment guideline [33] or from South Africa guideline on CAP for the regional perspectives [17] or international references [28].

Very few clinicians had essential knowledge of atypical pathogens and these were not covered in the empiric antibiotic regimen in both non-severe and severe pneumonia. We could find that atypical species like Coxiella spp are not covered well by the experience of clinicians from Kilimanjaro region [22]. Therefore there is a missed focused for atypical pathogens, especially in patients with severe pneumonia. Our study brings up a concern of missed opportunities for diagnosis and treatment of atypical pneumonia like $\mathrm{Q}$ fever in Kilimanjaro region and so Tanzania as a representative of sub-Saharan Africa.

The clear need for the evidence based guideline to treat LRTI in sub-Saharan African countries needs to set into practice accordingly.

\section{Study Limitations}

One big limitation of the study is the lack enough records in the files as some tests might have been requested, but not recorded in the files. I was hard to estimate the time taken from the point of prescription to the point of administering the medication.

There was a limitation of funds, that made our study design to be a cross-sectional rather than a longitudinal one. The time to conduct a follow up of patients after health care. This means outcome of care and the current practice was difficult to study as a course of association. Due to a limitation of funds larger sample size was not easily attained but through the use of qualitative design it will be feasible to conclude from the results.

The design of the study contains qualitative approach and therefore the investigator has used semi structured questionnaires in which associations might be studied.

\section{CONCLUSION}

It is possible to work on the parameters for assessing the severity of illness for lower respiratory tract infec- tion. Management of lower respiratory tract infection and atypical pneumonia shall be guided by the local audits reflected by the national guidelines.

\section{ACKNOWLEDGEMENTS}

Appreciation to Nijmegen University Medical College (UMCN)of Radboud University for the support. I acknowledge Quirijn de Mast, Marlies Hulscher, Andre van der Ven from the UMCN for the technical assitance provided for the study design.I also acknowldge, Patrick Kweka and Angelique Slot for data collection, Marycellina Msuya of KCMC nursing college Prof Gibson Kibiki and Prof Moshi Ntabaye for their technical input in logistics.

\section{RECOMMENDATIONS}

There is a need of strengthening the local audits for maping the gaps of quality improvement. The tool for high suspicion of atypical pneumonia and severity index shall be developed and its use must be well guiding the health care workers.

\section{COMPETING INTERESTS}

The study was funded by the Radboud University Nijmegen Medical Centre, Institute of Quality of Healthcare as the pilot study for development of a research project for improving quality of lower respiratory tract infection in Tanzania. The author does not hold any stocks or shares in an organization that may in any way might be affected by this publication.

\section{AUTHORS' CONTRIBUTION}

BM developed a concept of research work, proposal development, data collection, database development, analysis, report writing and writing of the manuscript.

\section{AUTHOR'S INFORMATION}

$\mathrm{BM}$ is a Tanzanian medical doctor and a clinical researcher who worked at Kilimanjaro Clinical Research Institute of Kilimanjaro Christian Medical Centre, Moshi Tanzania. He is currently working for Christian Social Service Commission as a CQI specialist.

\section{REFERENCES}

[1] Lozano, R., Naghavi, M., Foreman, K., Lim, S., Shibuya, K., et al. (2012) Global and regional mortality from 235 causes of death for 20 age groups in 1990 and 2010: A systematic analysis for the Global Burden of Disease Study 2010. Lancet, 380, 2095-2128. http://dx.doi.org/10.1016/S0140-6736(12)61728-0

[2] Murray, C.J. and Lopez, A.D. (1996) Evidence-based health policy-Lessons from the Global Burden of Disease Study. Science, 274, 740-743. http://dx.doi.org/10.1126/science.274.5288.740

[3] Michaud, C.M., Murray, C.J. and Bloom, B.R. (2001) Burden of disease-Implications for future research. JAMA, 285, 535-539. 
http://dx.doi.org/10.1001/jama.285.5.535

[4] Bates, M., Mudenda, V., Mwaba, P. and Zumla, A. (2013) Deaths due to respiratory tract infections in Africa: A review of autopsy studies. Current Opinion in Pulmonary Medicine, 19, 229-237. http://dx.doi.org/10.1097/MCP.0b013e32835f4fe4

[5] Beaglehole, R. (2004) The World Health Report 2004Changing History. Geneva, 120-124.

[6] Sligl, W.I. and Marrie, T.J. (2013) Severe community-acquired pneumonia. Critical Care Clinics, 29, 563-601. http://dx.doi.org/10.1016/j.ccc.2013.03.009

[7] Mizgerd, J.P. (2006) Lung infection-A public health priority. PLOS Medicine, 3, e76. http://dx.doi.org/10.1371/journal.pmed.0030076

[8] Mathers, C.D., Boerma, T. and Ma Fat, D. (2009) Global and regional causes of death. British Medical Bulletin, 92, 7-32. http://dx.doi.org/10.1093/bmb/ldp028

[9] Hoffken, G., Lorenz, J., Kern, W., Welte, T., Bauer, T., et al. (2010) Guidelines for the epidemiology, diagnosis, antimicrobial therapy and management of community-acquired pneumonia and lower respiratory tract infections in adults. Deutsche Medizinische Wochenschrift, 135, 359365.

[10] Feldman, C. and Anderson, R. (2013) HIV-associated bacterial pneumonia. Clinics in Chest Medicine, 34, 205216. http://dx.doi.org/10.1016/j.ccm.2013.01.006

[11] Feldman, C. and Anderson, R. (2012) Antibiotic resistance of pathogens causing community-acquired pneumonia. Seminars in Respiratory and Critical Care Medicine, 33, 232-243. http://dx.doi.org/10.1055/s-0032-1315635

[12] Mudhune, S. and Wamae, M. (2009) Network surveillance for pneumococcal disease in the East African Region. Report on invasive disease and meningitis due to Haemophilus influenzae and Streptococcus pneumonia from the network for surveillance of pneumococcal disease in the East African Region. Clinical Infectious Diseases, 48, S147-S152. http://dx.doi.org/10.1086/596494

[13] Mandell, L.A., Wunderink, R.G., Anzueto, A., Bartlett, J.G., Campbell, G.D., et al. (2007) Infectious diseases society of America/American thoracic society consensus guidelines on the management of community-acquired pneumonia in adults. Clinical Infectious Diseases, 44, S27-S72. http://dx.doi.org/10.1086/511159

[14] Macfarlane, J.T. and Boldy, D. (2004) 2004 update of BTS pneumonia guidelines: What's new? Thorax, 59, 364-366. http://dx.doi.org/10.1136/thx.2004.024992

[15] Menendez, R., Torres, A., Aspa, J., Capelastegui, A., Prat, C., et al. (2010) Community acquired pneumonia. New guidelines of the Spanish Society of Chest Diseases and Thoracic Surgery (SEPAR). Archivos de Bronconeumología, 46, 543-558. http://dx.doi.org/10.1016/S1579-2129(11)60008-6

[16] American Thoracic Society (2005) Guidelines for the management of adults with hospital-acquired, ventilatorassociated, and healthcare-associated pneumonia. American Journal of Respiratory and Critical Care Medicine, 171, 388-416.
http://dx.doi.org/10.1164/rccm.200405-644ST

[17] Working Group of the South African Thoracic Society (2007) Management of community-acquired pneumonia in adults. South African Medical Journal, 97, 1295-1306.

[18] Heppner, H.J., Sehlhoff, B., Niklaus, D., Pientka, L. and Thiem, U. (2011) Pneumonia severity index (PSI), CURB65 , and mortality in hospitalized elderly patients with aspiration pneumonia. Zeitschrift für Gerontologie und Geriatrie, 44, 229-234. http://dx.doi.org/10.1007/s00391-011-0184-3

[19] Cunha, B.A. (2006) The atypical pneumonias: Clinical diagnosis and importance. Clinical Microbiology and Infection, 12, 12-24. http://dx.doi.org/10.1111/j.1469-0691.2006.01393.x

[20] Hartung, T.K., Chimbayo, D., van Oosterhout, J.J., Chikaonda, T., van Doornum, G.J., et al. (2011) Etiology of suspected pneumonia in adults admitted to a high-dependency unit in Blantyre, Malawi. American Society of Tropical Medicine and Hygiene, 85, 105-112.

http://dx.doi.org/10.4269/ajtmh.2011.10-0640

[21] Kim, C., Nyoka, R., Ahmed, J.A., Winchell, J.M., Mitchell, S.L., et al. (2012) Epidemiology of respiratory infections caused by atypical bacteria in two Kenyan refugee camps. Journal of Immigrant and Minority Health, 14, 140-145. http://dx.doi.org/10.1007/s10903-011-9494-1

[22] Prabhu, M., Nicholson, W.L., Roche, A.J., Kersh, G.J., Fitzpatrick, K.A., et al. (2011) Q fever, spotted fever group, and typhus group rickettsioses among hospitalized febrile patients in northern Tanzania. Clinical Infectious Diseases, 53, e8-e15. http://dx.doi.org/10.1093/cid/cir411

[23] Cunha, B.A., Pherez, F. and Walls, N. (2009) Severe cytomegalovirus (CMV) community-acquired pneumonia (CAP) in a nonimmunocompromised host. Heart Lung, 38, 243-248. http://dx.doi.org/10.1016/j.hrtlng.2008.05.008

[24] Kibiki, G.S., Mulder, B., van der Ven, A.J., Sam, N., Boeree, M.J., et al. (2007) Laboratory diagnosis of pulmonary tuberculosis in TB and HIV endemic settings and the contribution of real time PCR for M. tuberculosis in bronchoalveolar lavage fluid. Tropical Medicine \& International Health, 12, 1210-1217. http://dx.doi.org/10.1111/j.1365-3156.2007.01907.x

[25] Semvua, H.H. and Kibiki, G.S. (2011) AtriplaR/anti-TB combination in TB/HIV patients. Drug in focus. BMC Research Notes, 4, 511. http://dx.doi.org/10.1186/1756-0500-4-511

[26] Kabali, C., von Reyn, C.F., Brooks, D.R., Waddell, R., Mtei, L., et al. (2011) Completion of isoniazid preventive therapy and survival in HIV-infected, TST-positive adults in Tanzania. International Journal of Tuberculosis and Lung Disease, 15, 1515-1521. http://dx.doi.org/10.5588/ijtld.10.0788

[27] Thiem, U., Heppner, H.J. and Pientka, L. (2011) Elderly patients with community-acquired pneumonia: Optimal treatment strategies. Drugs Aging, 28, 519-537. http://dx.doi.org/10.2165/11591980-000000000-00000

[28] Wiersinga, W.J., Bonten, M.J., Boersma, W.G., Jonkers, R.E., Aleva, R.M., et al. (2012) SWAB/NVALT (Dutch 
Working Party on Antibiotic Policy and Dutch Association of Chest Physicians) guidelines on the management of community-acquired pneumonia in adults. Netherlands Journal of Medicine, 70, 90-101.

[29] Watkins, R.R. and Lemonovich, T.L. (2011) Diagnosis and management of community-acquired pneumonia in adults. American Family Physician, 83, 1299-1306.

[30] Arnold, F.W., La Joie, A.S., Brock, G.N., Peyrani, P., Rello, J., et al. (2009) Improving outcomes in elderly patients with community-acquired pneumonia by adhering to national guidelines: Community-Acquired Pneumonia Organization International cohort study results. Archives of Internal Medicine, 169, 1515-1524. http://dx.doi.org/10.1001/archinternmed.2009.265

[31] Menendez, R., Ferrando, D., Valles, J.M. and Vallterra, J. (2002) Influence of deviation from guidelines on the outcome of community-acquired pneumonia. Chest, 122, 612-617. http://dx.doi.org/10.1378/chest.122.2.612

[32] Nyamande, K. and Lalloo, U.G. (2007) Poor adherence to South African guidelines for the management of community-acquired pneumonia. South African Medical Journal,

\section{ABBREVIATIONS}

CAP: community acquired pneumonia

CRF: case report forms
97, 601-603.

[33] Ministry of Health and Social Welfare, The Government of Tanzania (2007) Standard Treatment Guidelines (STG) and the National Essential Medicines List (NEMLIT) for mainland Tanzania. Dar es Salaam.

[34] National Tuberculosis and Leprosy Control Programme, NTLP (2008) Management of TB/HIV co-infected patients Manual for Health Care Workers at TB clinics and HIV Care \& Treatment Centers. Ministry of Health and Social Welfare, Dar es Salaam.

[35] Ntuli, A.K., Kabengula, J.S. and Msuya, S.E. (2011) Perceived barriers and attitudes of health care providers towards Provider-Initiated HIV Testing and Counseling in Mbeya region, southern highland zone of Tanzania. Pan African Medical Journal, 8, 17.

[36] Tribble, A.C., Hamilton, C.D., Crump, J.A., Mgonja, A., Mtalo, A., et al. (2009) Missed opportunities for diagnosis of tuberculosis and human immunodeficiency virus co-infection in Moshi, Tanzania. International Journal of Tuberculosis and Lung Disease, 13, 1260-1266.

LRTI: lower respiratory tract infection

PITC: provider initiated testing and counseling 


\section{APPENDIX}

Table A1. The summary of treatment patterns for LRTI in the patient files within the hospitals of Kilimanjaro region.

\begin{tabular}{|c|c|c|c|c|c|c|c|c|c|c|c|c|c|c|}
\hline & & \multicolumn{2}{|c|}{$\begin{array}{c}\text { Zonal Refarral } \\
\text { hospital }\end{array}$} & \multicolumn{2}{|c|}{$\begin{array}{c}\text { Regional } \\
\text { hospital }\end{array}$} & \multicolumn{2}{|c|}{$\begin{array}{l}\text { District } \\
\text { hospital }\end{array}$} & \multicolumn{2}{|c|}{$\begin{array}{l}\text { Health } \\
\text { center }\end{array}$} & \multicolumn{2}{|c|}{$\begin{array}{c}\text { Independent } \\
\text { hospital }\end{array}$} & \multirow{2}{*}{$\begin{array}{l}\text { Total } \\
\text { Total }\end{array}$} & \multirow[t]{2}{*}{$\begin{array}{c}\text { Pearson } \\
\text { Chi } \chi^{2} \text { df (4) }\end{array}$} & \multirow[t]{2}{*}{ P value } \\
\hline & & $\mathrm{n}$ & $\%$ & $\mathrm{n}$ & $\%$ & $\mathrm{n}$ & $\%$ & $\mathrm{n}$ & $\%$ & $\mathrm{n}$ & $\%$ & & & \\
\hline \multirow[t]{14}{*}{ Antibiotics } & Benzylpenicillin & 10 & 9.90 & 19 & 20.88 & 45 & 49.45 & 18 & 19.78 & 9 & 9.89 & 191 & 33.4506 & $<0.001$ \\
\hline & Amoxicillin & 15 & 12.50 & 11 & 10.48 & 44 & 41.9 & 37 & 35.24 & 13 & 12.38 & 205 & 26.4155 & $<0.001$ \\
\hline & Ampicillin & 46 & 61.33 & 0 & 0 & 27 & 93.1 & 1 & 3.45 & 1 & 3.45 & 129 & 74.3495 & $<0.001$ \\
\hline & Ampiclox & 4 & 25.0 & 2 & 9.52 & 18 & 85.71 & 1 & 4.76 & 0 & 0 & 21 & 13.179 & 0.002 \\
\hline & Chloramphenicol & 4 & 25.0 & 2 & 16.67 & 5 & 41.67 & 5 & 41.67 & 0 & 0 & 12 & 2.9636 & 0.564 \\
\hline & Gentamycin & 2 & 5.40 & 1 & 2.86 & 28 & 80 & 5 & 14.29 & 1 & 2.86 & 35 & 29.2360 & $<0.001$ \\
\hline & Ceftriaxone & 24 & 48.0 & 3 & 11.54 & 19 & 73.08 & 2 & 7.69 & 2 & 7.69 & 26 & 19.4613 & 0.001 \\
\hline & Co-trimoxazole & 8 & 23,53 & 7 & 26.92 & 7 & 26.92 & 7 & 26.92 & 5 & 19.23 & 26 & 9.9445 & 0.041 \\
\hline & Cloxacillin & 9 & 34.62 & 0 & 0 & 17 & 100 & 0 & 0 & 0 & 0 & 17 & 17.8233 & 0.001 \\
\hline & Metronidazole & 24 & 54.55 & 2 & 10 & 14 & 70 & 4 & 20 & 0 & 0 & 20 & 23.4046 & $<0.001$ \\
\hline & Doxycycline & 1 & 16.67 & 0 & 0 & 2 & 40 & 3 & 60 & 0 & 0 & 5 & 4.1769 & 0.383 \\
\hline & Erythromycin & 0 & 0.00 & 6 & 33.33 & 8 & 44.44 & 3 & 16.67 & 1 & 5.56 & 18 & 18.3013 & 0.001 \\
\hline & Azithromycin & 4 & 50.0 & 1 & 25 & 2 & 50 & 1 & 25 & 0 & 0 & 4 & 3.0064 & 0.557 \\
\hline & Ciprofloxacin & 1 & 11.11 & 0 & 0 & 3 & 37.5 & 2 & 25 & 3 & 37.5 & 8 & 8.1938 & 0.085 \\
\hline \multicolumn{2}{|c|}{ Anti-TB treatment } & 10 & 37.04 & 6 & 35.29 & 8 & 47.06 & 0 & 0 & 3 & 17.65 & 17 & 13.2505 & 0.010 \\
\hline \multicolumn{2}{|c|}{ Anti-retrovirals } & 5 & 62.50 & 1 & 33.33 & 2 & 66.67 & 0 & 0 & 0 & 0 & 3 & 6.6865 & 0.153 \\
\hline \multirow[t]{3}{*}{ Bronchodila } & Aminophylline & 10 & 15.63 & 8 & 14.81 & 25 & 46.3 & 17 & 31.48 & 4 & 7.41 & 54 & 7.2743 & 0.122 \\
\hline & Salbutamol & 8 & 25.0 & 1 & 4.17 & 13 & 54.17 & 6 & 25 & 4 & 16.67 & 24 & 2.1817 & 0.702 \\
\hline & Hydrocortisone & 15 & 36.59 & 4 & 15.38 & 18 & 69.23 & 2 & 7.69 & 2 & 7.69 & 26 & 8.4970 & 0.075 \\
\hline
\end{tabular}

Table A2. The summary of Additional treatment options for LRTI found in the patient files hospitals of Kilimanjaro region.

\begin{tabular}{|c|c|c|c|c|c|c|c|c|c|c|c|c|c|c|}
\hline & & \multicolumn{2}{|c|}{$\begin{array}{c}\text { Zonal Refarral } \\
\text { hospital }\end{array}$} & \multicolumn{2}{|c|}{$\begin{array}{l}\text { Regional } \\
\text { hospital }\end{array}$} & \multicolumn{2}{|c|}{$\begin{array}{l}\text { District } \\
\text { hospital }\end{array}$} & \multicolumn{2}{|c|}{$\begin{array}{l}\text { Health } \\
\text { center }\end{array}$} & \multicolumn{2}{|c|}{$\begin{array}{c}\text { Independent } \\
\text { hospital }\end{array}$} & \multirow{2}{*}{$\begin{array}{l}\text { Total } \\
\text { Total }\end{array}$} & \multirow[t]{2}{*}{$\begin{array}{c}\text { Pearson } \\
\text { Chi } \chi^{2} \text { df (4) }\end{array}$} & \multirow[t]{2}{*}{$P$ value } \\
\hline & & $\mathrm{n}$ & $\%$ & $\mathrm{n}$ & $\%$ & $\mathrm{n}$ & $\%$ & $\mathrm{n}$ & $\%$ & $\mathrm{n}$ & $\%$ & & & \\
\hline \multirow[t]{3}{*}{ Anti-pain } & Asprin & 9 & 56.2 & 0 & 0 & 1 & 14.29 & 6 & 85.71 & 0 & 0 & 7 & 15.3718 & 0.004 \\
\hline & Diclofenac & 4 & 14.8 & 1 & 4.35 & 12 & 52.17 & 8 & 34.78 & 2 & 8.7 & 23 & 4.5277 & 0.339 \\
\hline & Ibuprofen & 0 & 0.0 & 0 & 0 & 2 & 22.22 & 1 & 11.11 & 6 & 66.67 & 9 & 27.1467 & $<0.001$ \\
\hline \multirow[t]{4}{*}{$\begin{array}{l}\text { Paliative } \\
\text { medication }\end{array}$} & Cough Syp & 2 & 3.1 & 7 & 11.11 & 22 & 34.92 & 22 & 34.92 & 12 & 19.05 & 63 & 34.1011 & $<0.001$ \\
\hline & IV infusion & 18 & 36.7 & 9 & 29.03 & 18 & 58.06 & 2 & 6.45 & 2 & 6.45 & 31 & 16.2837 & 0.003 \\
\hline & Vitamin B complex & 2 & 7.4 & 5 & 20 & 12 & 48 & 6 & 24 & 2 & 8 & 25 & 7.7523 & 0.101 \\
\hline & Oxygen & 10 & 58.8 & 0 & 0 & 7 & 100 & 0 & 0 & 0 & 0 & 7 & 13.7781 & 0.008 \\
\hline \multirow[t]{2}{*}{ Anti-histamine } & Prednisolone & 4 & 26.7 & 0 & 0 & 7 & 63.64 & 1 & 9.09 & 3 & 27.27 & 11 & 5.5537 & 0.235 \\
\hline & Chlorpheniramine & 0 & 0.0 & 0 & 0 & 3 & 18.75 & 11 & 68.7 & 2 & 12.5 & 16 & 28.2253 & $<0.001$ \\
\hline
\end{tabular}

Table A3. The summary of treatment options for co-morbidities among patients presenting with LRTI as done by clinicians in the hospitals of Kilimanjaro region.

\begin{tabular}{|c|c|c|c|c|c|c|c|c|c|c|c|c|c|c|}
\hline & & \multicolumn{2}{|c|}{$\begin{array}{l}\text { Refferal } \\
\text { hospital }\end{array}$} & \multicolumn{2}{|c|}{$\begin{array}{c}\text { Regional } \\
\text { hospital }\end{array}$} & \multicolumn{2}{|c|}{$\begin{array}{l}\text { District } \\
\text { hospital }\end{array}$} & \multicolumn{2}{|c|}{$\begin{array}{l}\text { Health } \\
\text { center }\end{array}$} & \multicolumn{2}{|c|}{$\begin{array}{c}\text { Independent } \\
\text { hospital }\end{array}$} & \multirow{2}{*}{$\begin{array}{l}\text { Total } \\
\text { Total } \\
\end{array}$} & \multirow[t]{2}{*}{$\begin{array}{c}\text { Pearson } \\
\text { Chi } \chi^{2}\end{array}$} & \multirow[t]{2}{*}{$P$ value } \\
\hline & & $\mathrm{n}$ & $\%$ & $\mathrm{n}$ & $\%$ & Frequency & $\%$ & Frequency & $\%$ & Frequency & $\%$ & & & \\
\hline \multirow[t]{2}{*}{$\begin{array}{c}\text { Anti-malaria } \\
\text { treatment }\end{array}$} & Quinine & 5 & 23.8 & 2 & 12.5 & 14 & 87.5 & 0 & 0 & 0 & 0 & 16 & 12.1769 & 0.016 \\
\hline & ALU & 3 & 11.11 & 1 & 4.17 & 13 & 54.17 & 10 & 41.67 & 0 & 0 & 24 & 11.7553 & 0.019 \\
\hline \multirow[t]{2}{*}{ Anti-worms } & Mebendazole & 0 & 0.00 & 3 & 42.86 & 1 & 14.29 & 3 & 42.86 & 0 & 0 & 7 & 14.5827 & 0.006 \\
\hline & Albendazole & 1 & 12.5 & 3 & 42.86 & 3 & 42.86 & 1 & 14.29 & 0 & 0 & 7 & 8.9843 & 0.061 \\
\hline \multirow{4}{*}{$\begin{array}{c}\text { Anti-acids } \\
\text { Cardiovascular } \\
\text { medication }\end{array}$} & Furosemide & 32 & 62.75 & 2 & 10.53 & 11 & 57.89 & 3 & 15.79 & 3 & $\begin{array}{c}15.7 \\
9\end{array}$ & 19 & 40.9197 & $<0.001$ \\
\hline & Captopril & 13 & 93.8 & 0 & 0 & 0 & 0 & 1 & 100 & 0 & 0 & 1 & 33.1019 & $<0.001$ \\
\hline & Digoxin & 7 & 58.33 & 1 & 20 & 2 & 40 & 1 & 20 & 1 & 20 & 5 & 6.8317 & 0.145 \\
\hline & Nifedipine & 7 & 46.67 & 0 & 0 & 6 & 75 & 2 & 25 & 0 & 0 & 8 & 5.5251 & 0.238 \\
\hline \multirow{2}{*}{$\begin{array}{l}\text { Anti-diabetic } \\
\text { treatment }\end{array}$} & Metformine & 2 & 66.67 & 0 & 0 & 1 & 100 & 0 & 0 & 0 & 0 & 1 & 2.9628 & 0.564 \\
\hline & Diabenes & 1 & 33.33 & 0 & 0 & 2 & 100 & 0 & 0 & 0 & 0 & 2 & 1.9613 & 0.743 \\
\hline
\end{tabular}

Note: These were the medications used to treat comorbidities and differential dignoses reported in the files of patients admitted for symptoms that were mimicking or related to lower respiratory tract infections. 